PERIODICALS OF ENGINEERING AND NATURAL SCIENCES

Vol. 5 No. 1 (2017) - Special Issue (Recent Topics in Environmental Science)

Available online at: http://pen.ius.edu.ba

\title{
A Comparison of Perturb \& Observe and Fuzzy-Logic Based MPPT Methods for Uniform Environment Conditions
}

\author{
Ekrem Kandemir \\ Solar Energy Institute, Ege University, Izmir, \\ Turkey \\ ekremkdemir@gmail.com
}

\author{
Numan S. Cetin \\ Solar Energy Institute, Ege University, Izmir, \\ Turkey
}

\author{
Selim Borekci \\ Faculty of Engineering, Electrical - Electronic \\ Engineering, Akdeniz University, Antalya, \\ Turkey
}

\begin{abstract}
The power generation from photovoltaic $(P V)$ system is not constant and it varies based on solar irradiance and temperature. For any environmental condition, to convert maximum available solar energy, PV systems must be operated at maximum power point. To accomplish that two different maximum power point tracking (MPPT) methods have been presented in this study. The first method can determine MPP point by measuring the derivative of $P V$ cell power $(d P)$ and $P V$ cell voltage $(d V)$ which is called Perturb \& Observe $(P \& O)$ method. The second method uses fuzzy-logic-control (FLC) based MPPT method to determine MPP point for actual environment conditions. In this paper, $3 \mathrm{~kW} P V$ system model is studied in MATLAB. According to the simulated results, FLC based MPPT method has better performance than $P \& O$ method. Compared to the $P \& O$ method, FLC-based MPPT can increase tracking accuracy and efficiency performance 0.13\% under standard test conditions (STC).
\end{abstract}

Keywords: PV model, PV characteristic curves, Maximum Power Point Tracking (MPPT), Perturb \& Observe (P\&O) Method, Fuzzy Logic Control (FLC)

\section{Introduction}

Demand for energy is increasing every day. Due to fossil fuel exhaustion and the environmental problems caused by the conventional power generation such as gasoline, coal, etc..., renewable energy sources such as photovoltaic panels and wind - generators are now widely used [1]. They are popular and environmental friendly energy sources $[2,3]$. When enough solar irradiance reaches PV panel, PV panel generates electrical power without any harmful effect to environment.

Recently, due to its development and cost reduction, PV systems become an efficient solution to the environment problem [4]. However, the development for improving the efficiency of the PV system is still a challenging field of research [5]. Efficiency of the PV panel system depends on load and environment condition.

Generated power from PV panels varies depending on electrical loads at the same environment condition. Because of that, generation of maximum available power is not guaranteed at all electrical loads [6]. Hence, Maximum available power can be generated at a specific point which is called Maximum Power Point (MPP). It is a single operating point given by a localized voltage and current for each environmental condition. The position of MPP point varies depending on solar irradiance, temperature and electrical load [7]. This problem requires a controller algorithm to find and track the MPP point for all atmospheric changes. In the literature, there are various maximum power point tracking methods used to operate PV systems at MPP.

Because of being simple and easy to implement, Perturb \& Observe $(\mathrm{P} \& \mathrm{O})$ method is one of the most used ones in the literature. However, this method presents some drawbacks. P\&O method shows convergence and oscillation problems around MPP region. Also, depending on small derivation parameters, it has slow response rate to reach MPP. To enhance the performance and remove these drawbacks of the P\&O method, this study presents Fuzzy Logic Control (FLC) based MPPT method. The simulation and a general comparison between P\&O and FLC based MPPTs are discussed in this paper. 


\section{Equivalent Circuit Model of PV Panels}

PV cells are $\mathrm{p}-\mathrm{n}$ junction semi - conductors that when exposed to light releases electrons around a closed electrical circuit [8]. In the literature, there are various types of PV cell equivalent circuit model. Commonly, single diode equivalent circuit model is used to express typical electrical characteristic of PV arrays [6].

A PV panel is built from connecting several PV cells in series or parallel. Figure 1 shows a PV cell equivalent circuit and a PV panel with 9 cells.

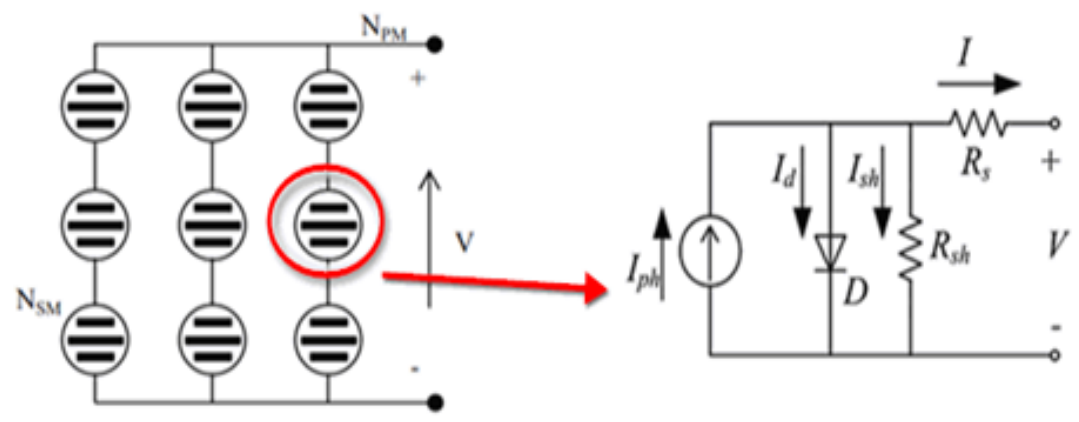

Figure 1. A PV panel and Equivalent circuit model of a PV cell

Electrons from the cell are excited to higher energy levels when a collision with a photon occurs. These electrons are free to move across the junction and create a current. This current is modelled by the light generated current source $\left(\mathrm{I}_{\mathrm{ph}}\right)$. The intrinsic $\mathrm{p}-\mathrm{n}$ junction characteristic of the PV cell is represented as a diode in the equivalent circuit model [9].

The PV load current show in Fig. 1 is defined as

$I=I_{p h}-I_{o}\left(e^{\frac{q\left(V+R_{s} I\right)}{A k T}}-1\right)-\frac{V+R_{s} I}{R_{s h}}$

where I and V represent PV cell output current and voltage. $\mathrm{R}_{\mathrm{S}}$ and $\mathrm{R}_{\mathrm{sh}}$ are the PV cell series and shunt resistance respectively. $\mathrm{I}_{\mathrm{ph}}$ is the PV cell photo current, $\mathrm{I}_{\mathrm{o}}$ is the diode saturation current, $\mathrm{A}$ is the diode quality factor $(\cong 1.2)$, $\mathrm{K}$ is Boltzmann's constant $\left(1.38 \times 10^{-23} \mathrm{~J} / \mathrm{K}\right)$ and $\mathrm{T}$ is the $\mathrm{PV}$ cell temperature in kelvins.

By using Eq. (1), the $3 \mathrm{~kW}$ PV panel system is modelled in MATLAB. As known by researches about PV cells and panels, solar irradiance and temperature affect PV panel operating point and electrical characteristics. In this context, the voltage - current and voltage - power characteristic curves are plotted for different solar irradiance and temperature values to show electrical changes.

Variation of solar irradiance affects PV panel power directly that PV power increases if solar irradiance increases. Figure 2 shows PV electrical characteristics curves for different solar irradiance levels (0-250-500-750-1000 $\left.\mathrm{W} / \mathrm{m}^{2}\right)$ at a constant temperature $\left(25^{\circ} \mathrm{C}\right)$. The maximum power occurs at around $80 \%$ of the open circuit voltage of PV panel.
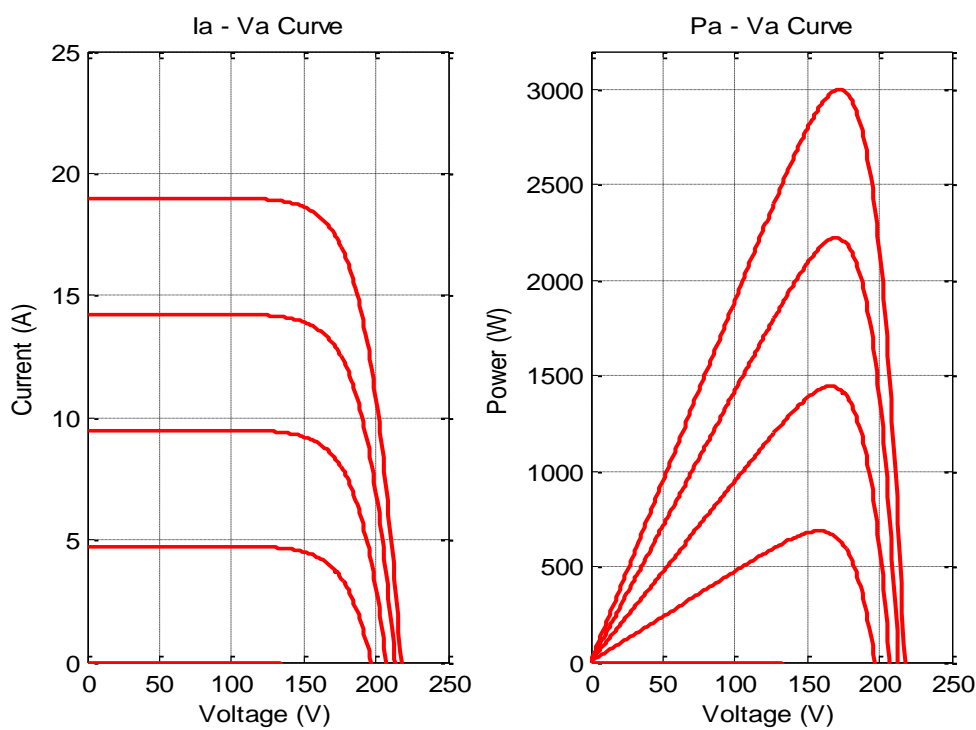

Figure 2. Current, voltage and power curves of PV panel under constant temperature and different solar irradiance 
Variation of ambient temperature also affects PV panel power inversely that PV power increases if ambient temperature decreases. Figure 3 shows PV electrical characteristics curves for different ambient temperature levels $\left(0^{\circ} \mathrm{C}, 25^{\circ} \mathrm{C}, 50^{\circ} \mathrm{C}, 75^{\circ} \mathrm{C}\right.$ and $\left.100^{\circ} \mathrm{C}\right)$ at a constant solar irradiance $\left(1000 \mathrm{~W} / \mathrm{m}^{2}\right)$. Unlike previous case, the maximum available power of the $\mathrm{PV}$ panel can be at different voltage level in different temperature.
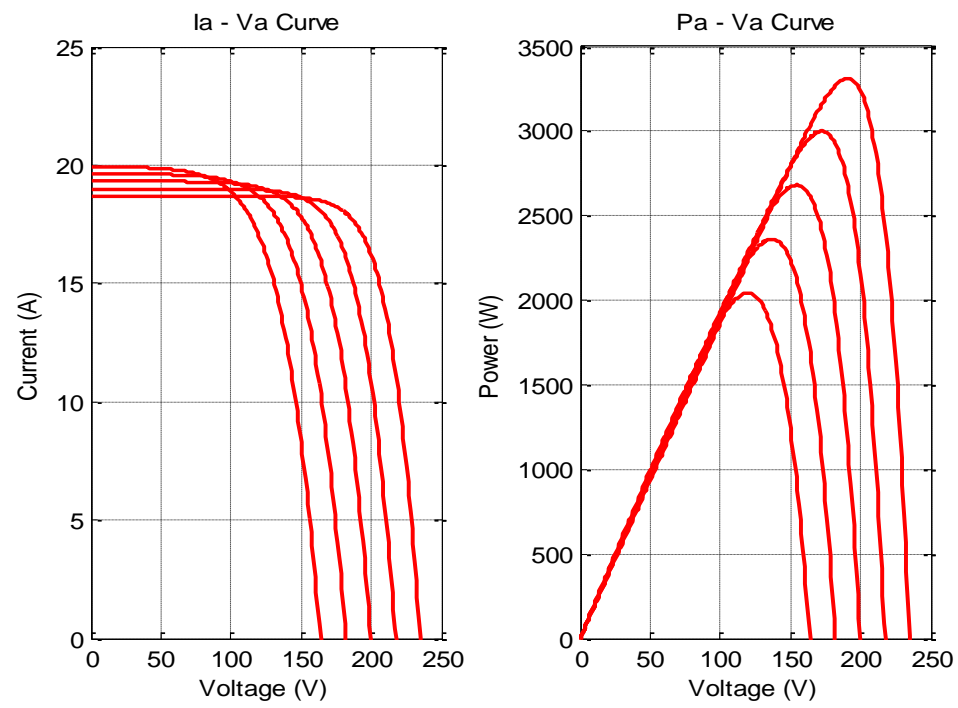

Figure 3. Current, voltage and power curves of PV panel under constant solar irradiance and different temperature

\section{Maximum Power Point Tracking Methods for PV Panels}

PV cells and panels generate different power depended on different environment condition and electrical load. Because of that, generation of maximum power is not guaranteed at all electrical loads [6]. Figure 4 illustrates maximum power point where PV panels operates maximum efficiency for a specific solar irradiance and temperature values. As shown in Figure 4, there is only one electrical load point which corresponds to the MPP for uniform environment condition. To utilize the PV panels on MPP, there are many MPPT algorithms have been developed and implemented by the researchers in the literature [10-11].

$$
G=1 \mathrm{~kW} / \mathrm{m}^{2}, T=25^{\circ} \mathrm{C}
$$
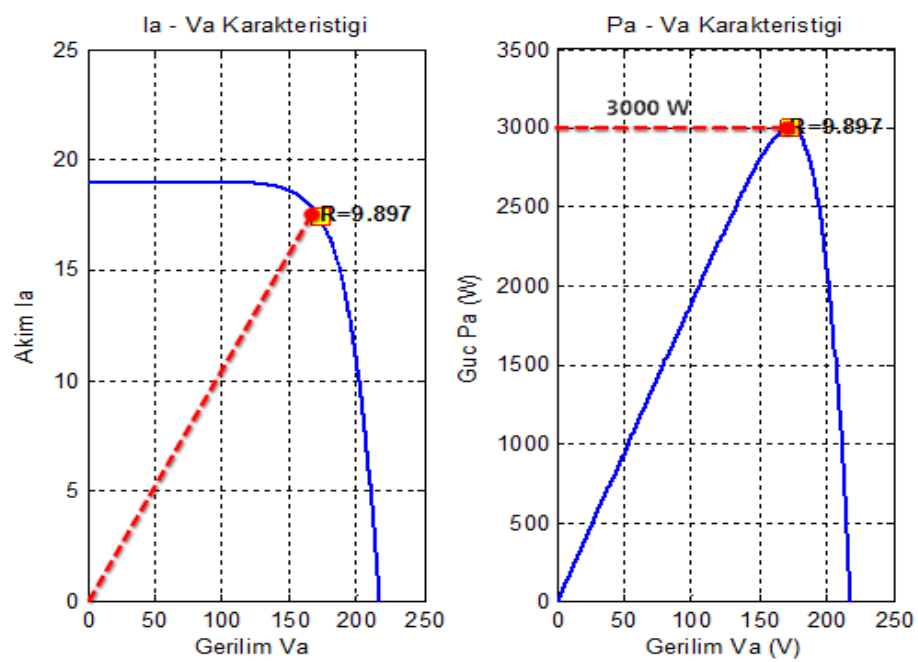

Figure 4. V-I and P-V curves for electrical load value of maximum power

To accomplish MPPT for 3kW PV system, two different MPPT methods are presented and compared in this study. The first method is $\mathrm{P} \& \mathrm{O}$ method which operates by periodically incrementing and decrementing the output voltage of the PV panel and compares output power of PV panel. The second method is fuzzy logic control (FLC) based MPPT method to determine MPP point. 


\subsection{Perturb \& Observe $(P \& O) M P P T$ Method}

One of the most and popular techniques of MPPT is the P\&O technique. The main concept of this method is to push the system to operate at the direction which the output power obtained from the PV system increases [5]. Basically, this method measures the derivative of PV panel power $(\mathrm{dP})$ and derivative of PV panel voltage $(\mathrm{dV})$ and uses PV power-voltage curve to determine the movement of the operating point. If the sign of $(\mathrm{dP} / \mathrm{dV})$ is positive, the actual point is in the left side of the MPP; else $(\mathrm{dP} / \mathrm{dV})$ is negative, the actual point is in the right side of the MPP. And this process continues until (dP/dV) equals to zero. The implementation of the $\mathrm{P} \& \mathrm{O}$ algorithm is shown in Figure 5.

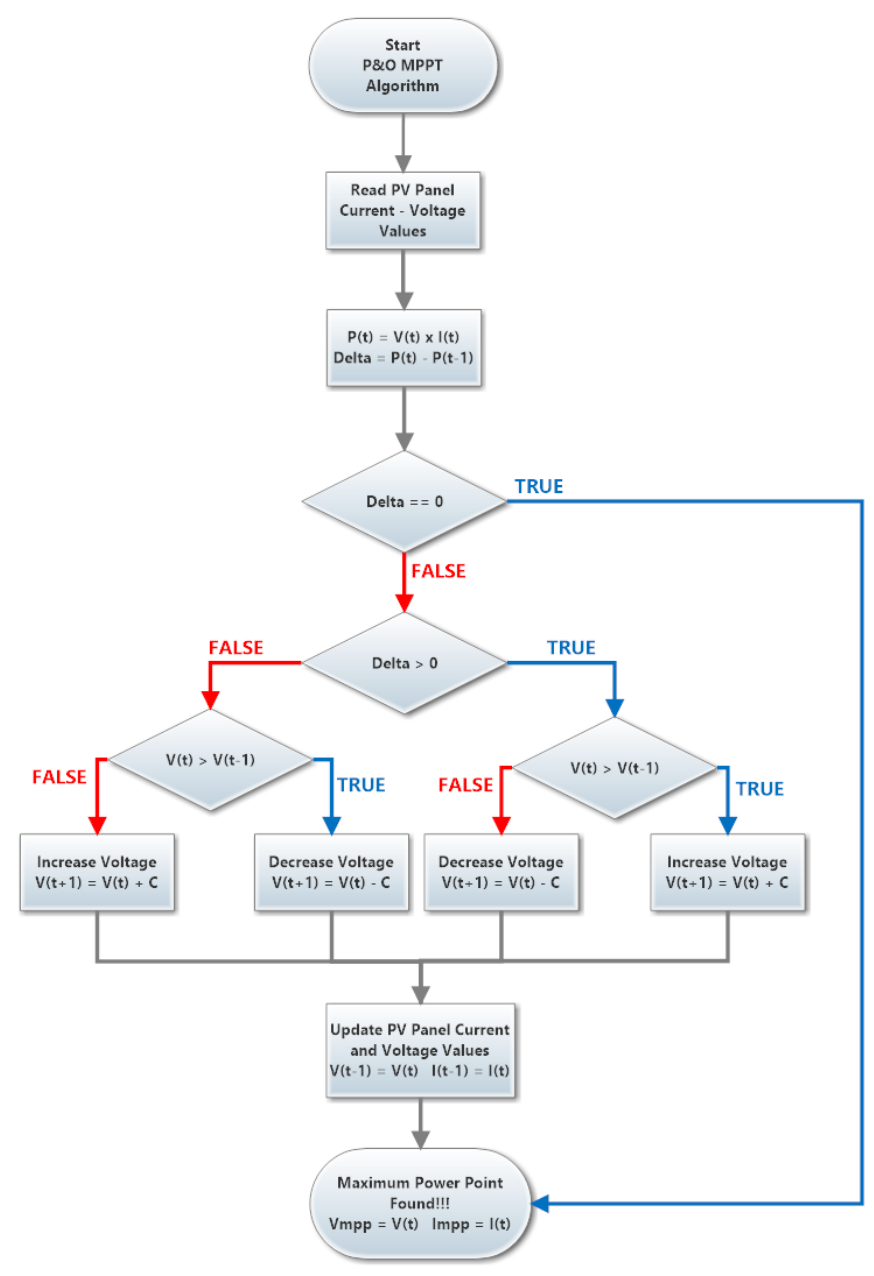

Figure 5. $P \& O$ maximum power point algorithm

This method works well in the steady state condition (solar irradiance and temperature changes slowly). However, the $\mathrm{P} \& \mathrm{O}$ method fails to track MPP when the environment condition is rapidly changed [5].

\subsection{Fuzzy Logic Control (FLC) MPPT Method}

Fuzzy logic control (FLC) based MPPT is one of the most used method to perform MPPT for any PV system in any environment condition. FLCs gain several advantages of better performance, robust and simple design. In addition, this method does not require the knowledge of the exact model of system [5]. The main parts of FLCs are examined in four parts, which are fuzzification, fuzzy rule-base, fuzzy inference engine and defuzzification. A general FLC control scheme is shown in Figure 6.

In the proposed FLC system, the input of FLC is sum of angle conductance $\left(\theta_{1}=\tan ^{-1}\left(d I_{p v} / d V_{p v}\right)\right)$ and angle of increment of conductance $\left(\theta_{2}=\tan ^{-1}\left(I_{p v} / V_{p v}\right)\right)$. The input variables are described in Eq. (2) and the MPPT determination condition was illustrated in Figure 7.

$\theta_{1}+\theta_{2}=\tan ^{-1}\left(\frac{d I_{p v}}{d V_{p v}}\right)+\tan ^{-1}\left(\frac{I_{p v}}{V_{p v}}\right)=0^{\circ}$

As seen in Figure 7, sum of the angles of PV panel conductance and increment of conductance equals to zero around MPPT point. Therefore, the membership function of the input and the rule base set of the FLC MPPT must 
be identified according to that condition for fuzzy inference system. In this context, the input variable of sum of angles $\left(\theta_{1}+\theta_{2}\right)$ is assigned to several linguistic variables which are denoted by NB (Negative Big), NS (Negative Small), ZE (Zero), PS (Positive Small) and PB (Positive Big). The membership functions for the input and output are illustrated in Figure 8 and the corresponding fuzzy rule set is shown in Figure 9.

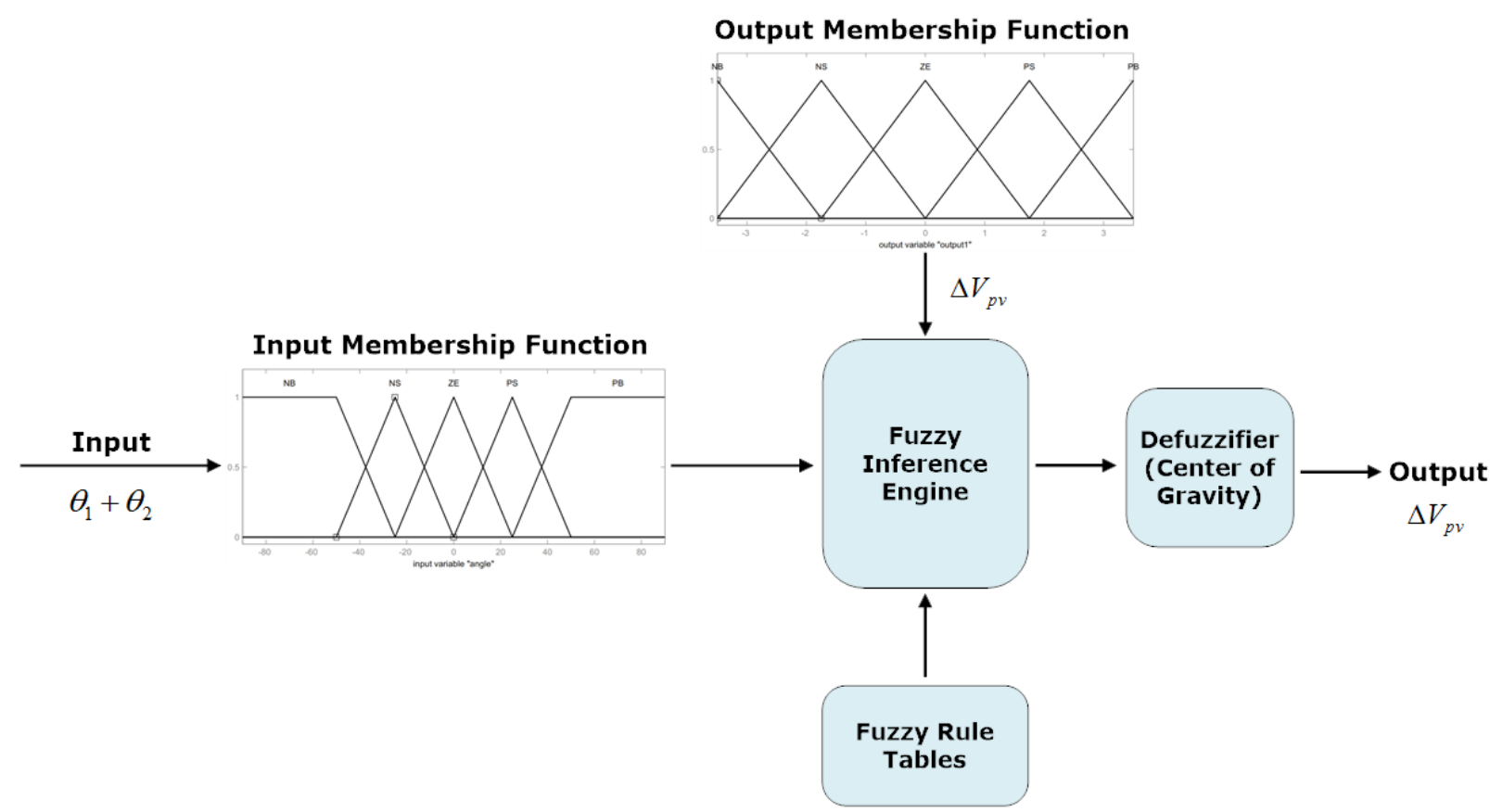

Figure 6. Block diagram of the proposed FLC-based MPPT system

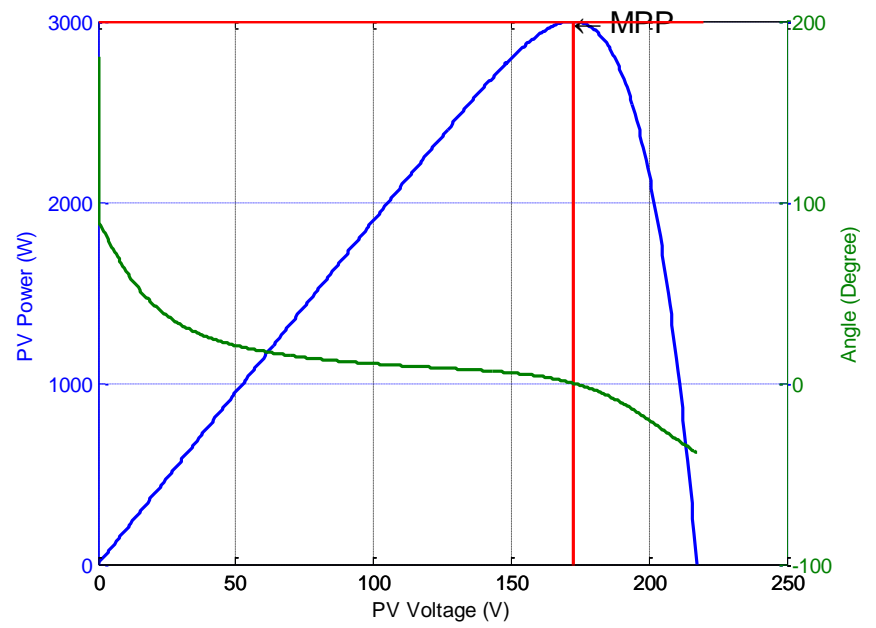

Figure 7. PV power - voltage and angle MPPT diagram for the proposed FLC-based MPPT system

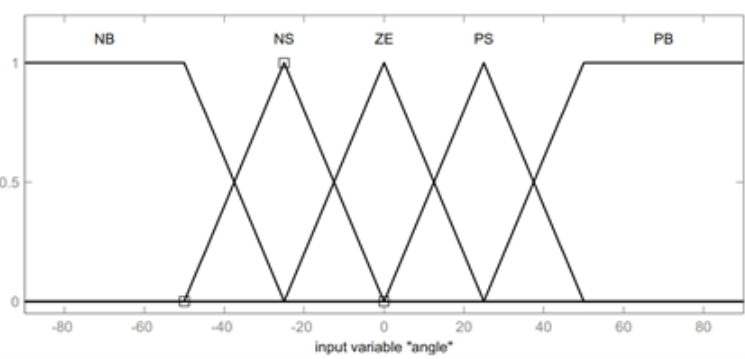

(a)

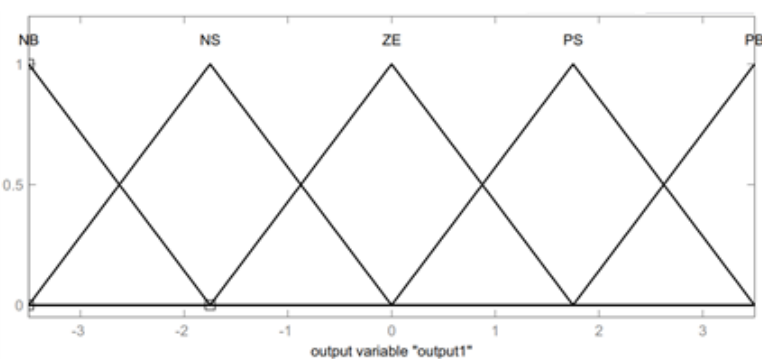

(b)

Figure 8. Membership functions for the FLC based MPPT (a) Membership function for input $\left(\theta_{1}+\theta_{2}\right)(b)$ Membership function for output $\left(\Delta V_{p v}\right)$ 


\begin{tabular}{|c|c|c|c|c|c|c|}
\hline $\boldsymbol{\theta}_{1}+\boldsymbol{\theta}_{2}$ & $\mathrm{NB}$ & $\mathrm{NS}$ & $\mathrm{ZE}$ & $\mathrm{PS}$ & $\mathrm{PB}$ \\
\hline$\Delta V_{p v}$ & $\mathrm{NB}$ & $\mathrm{NS}$ & ZE & $\mathrm{PS}$ & $\mathrm{PB}$ \\
\hline $\begin{array}{c}\text { Region } \\
\text { Area }\end{array}$ & \multicolumn{2}{|c|}{ Region 1 } & Region 2 & \multicolumn{2}{|c|}{ Region 3 } \\
\hline
\end{tabular}

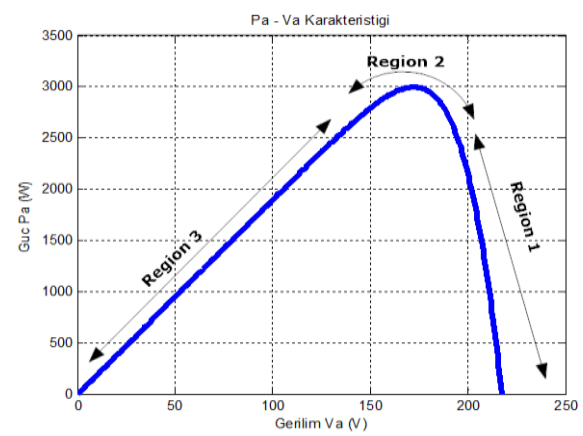

Figure 9. Fuzzy rules and PV power-voltage and angle MPPT diagram for the proposed FLC-based MPPT system

The defuzzification method used in this study is center of gravity method, which is one of the commonly used method in the literature shown in Eq. (3):

$Y_{C O G}=\frac{\sum_{i=1}^{n} Y_{i}\left(X_{i}\right) \times X_{i}}{\sum_{i=1}^{n} Y_{i}\left(X_{i}\right)}$

where $\boldsymbol{Y}_{\boldsymbol{i}}$ is the inference result of rule $\boldsymbol{i} ; \boldsymbol{X}_{\boldsymbol{i}}$ is the corresponding output value of rule $\boldsymbol{i}$; and $\boldsymbol{Y}_{\boldsymbol{C O} \boldsymbol{G}}$ is the output value of defuzzification process.

\section{Simulation Results of MPPTs and Discussion}

This study compares tracking performance and accuracy between P\&O method and FLC method using MATLAB. The performances of $\mathrm{P} \& \mathrm{O}$ method for $0.5 \mathrm{~V}$ and $3.5 \mathrm{~V}$ derivation parameters and FLC control method are shown in Figure 10. The simulations have been investigated under standard test conditions $\left(1000 \mathrm{~W} / \mathrm{m}^{2}-25^{\circ} \mathrm{C}\right)$.
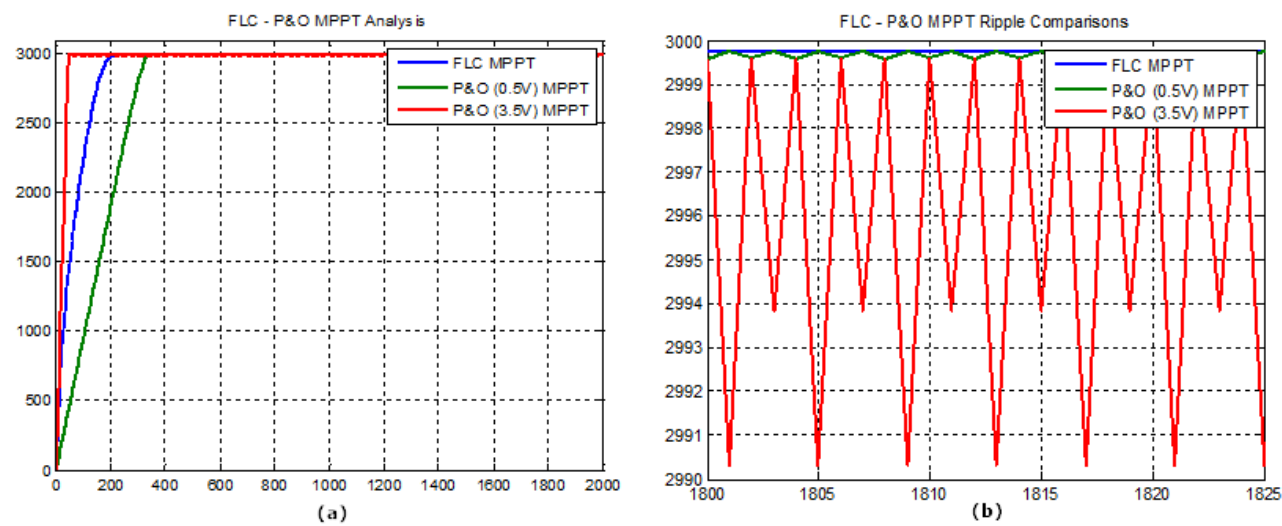

Figure 10. $P V$ power curves under standard test condition (a) $P \& O$ and FLC MPPT method response (b) $P \& O$ and FLC MPPT oscillations

As shown in Figure 10, $\mathrm{P} \& \mathrm{O}(3.5 \mathrm{~V}) \mathrm{MPPT}$ has the best response iteration rate but the worst accuracy performance because of more oscillations. The $\mathrm{P} \& \mathrm{O}(3.5 \mathrm{~V})$ method is 6.88 times iteration faster than $0.5 \mathrm{~V} P \& \mathrm{O}$ and 5.4 iteration times faster than FLC method. Nevertheless, its accuracy performance is almost $99.86 \%$ and worse than $\mathrm{P} \& \mathrm{O}(0.5 \mathrm{~V})$ and FLC MPPT method. The overall simulation results for response iteration rate, tracking accuracy performance are presented in Table 1.

Table 1. Comparison results for $P \& O$ and FLC MPPT

\begin{tabular}{cccc}
\hline MPPT & $\begin{array}{c}\text { Iteration } \\
\text { Number }\end{array}$ & $\begin{array}{c}\text { MPP Power } \\
(\mathrm{W})\end{array}$ & $\begin{array}{c}\text { Tracking } \\
\text { Accuracy }\end{array}$ \\
\hline P\&O (3.5V) & 50 & 2995.85 & $\% 99.86$ \\
P\&O (0.5V) & 344 & 2999.65 & $\% 99.98$ \\
FLC & 270 & 2999.7 & $\% 99.99$ \\
\hline
\end{tabular}

To highlight the FLC MPPT method performance, the following simulation results are shown in Figure 11 for different solar irradiance values $\left(1000-800-600-400 \mathrm{~W} / \mathrm{m}^{2}\right)$ at fixed temperature of $25^{\circ} \mathrm{C}$. The $\mathrm{P} \& \mathrm{O}(0.5 \mathrm{~V})$ algorithm has better MPPT accuracy than P\&O (3.5V) MPPT but slower response rate than FLC and P\&O (3.5V) MPPT methods. Also, oscillations remain around MPP. The FLC method has better response time than P\&O $(0.5 \mathrm{~V})$, and best MPPT accuracy performance (99.99\%). In addition, oscillations do not occur around MPP. Hence, 
the FLC MPPT method has increased $0.13 \%$ the tracking accuracy - performance compared to P\&O MPPT method.

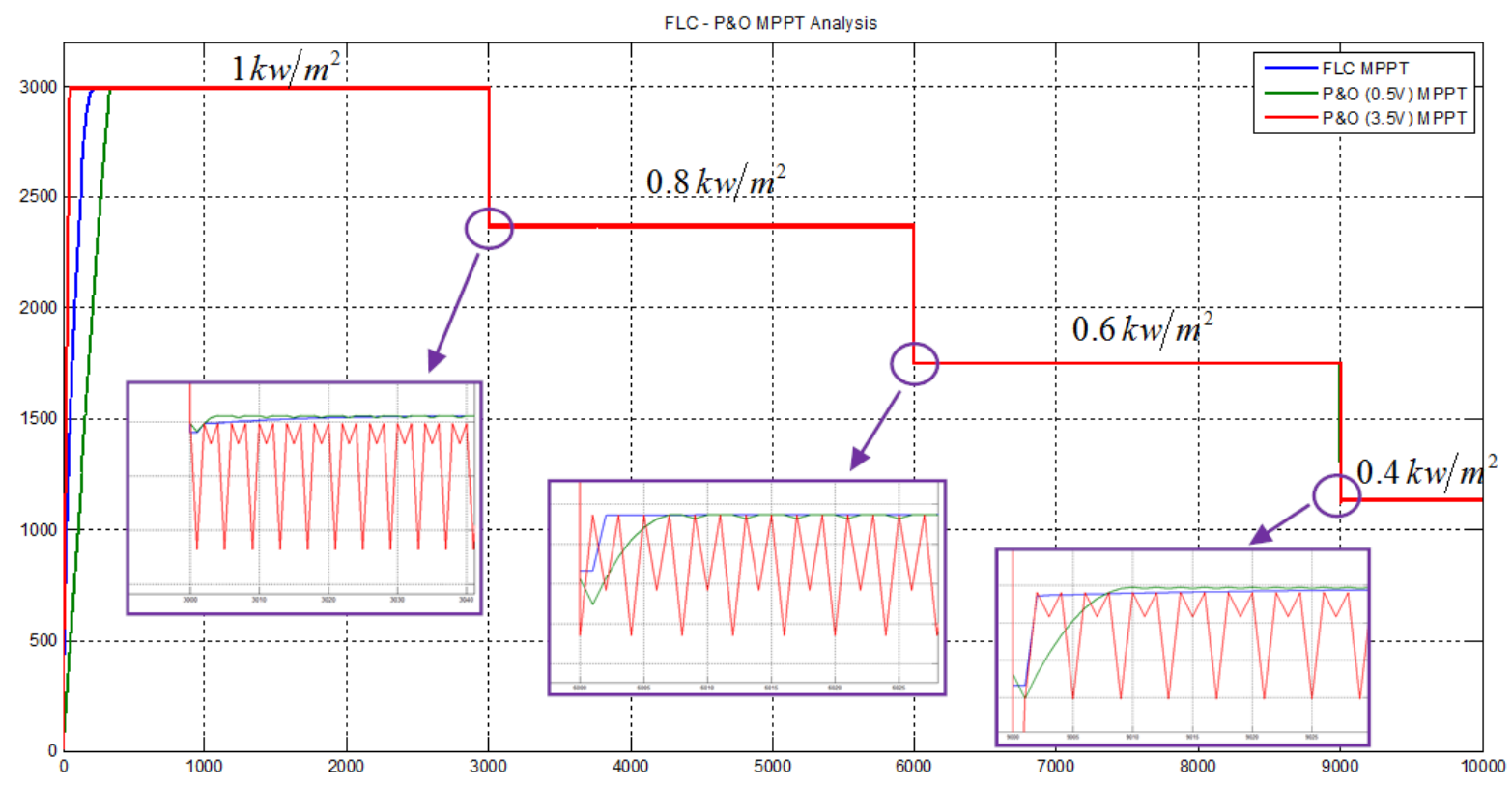

Figure 11. PV power curves under standard test condition (a) P\&O and FLC MPPT method response (b) P\&O and FLC MPPT oscillations

For practical application, the FLC method must be selected for its higher performance and acceptable response rate compared to P\&O method. The FLC method has better tracking efficiency and less oscillation at each step.

\section{Conclusions}

Photovoltaic power is one of the cleanest and abundant energy type in environment. It is practically free and inexhaustible in the world. According to the researches and applications, it is likely to be an alternative main source of power in the future. The power generation from PV systems depends on atmospheric changes like solar irradiance and temperature. Because of that fact, MPPT methods play important role to operate PV system at maximum efficiency for all environment condition. This paper presents electrical characteristics of $3 \mathrm{~kW} P V$ system and general comparison of FLC based and P\&O MPPT methods. Both MPPT methods are investigated and realized in MATLAB environment. The tracking accuracy and performance efficiency are compared in detail by simulation results in MATLAB. Based on the simulation results, it can be concluded that with both MPPT methods PV system can generate maximum power for actual environment condition. However, the tracking accuracy and performance of FLC MPPT is better and more convenient than P\&O MPPTs for PV system. FLC MPPT has no oscillations around MPP region and more stable output power than conventional MPPTs.

\section{References}

[1] Koutroulis E, Kalaitzakis K, Voulgaris NC. Development of a Microcontroller-Based Photovoltaic Maximum Power Point Tracking Control System. IEEE Transactions on Power Electronics 2001;16/1.

[2] Yadav APK, Thirumaliah S, Haritha G. Comparison of MPPT Algorithms for DC - DC Converters Based PV Systems. International Journal of Advanced Research in Electrical, Electronics and Instrumentation Engineering 2012:18-23.

[3] Hernanz JAR, Martin JJM, Belver IZ, Lesaka JL, Guerrero EZ, Perez EP. Modelling of Photovoltaic Module. International Conference on Renewable Energies and Power Quality 2010

[4] Subiyanto, Mohamed A, Hannan MA. Maximum Power Point Tracking in Grid Connected PV System Using A Novel Fuzzy Logic Controller. IEEE Student Conference on Research and Development 2009.

[5] Takun P, Kaitwanidvilai S, Jettanasen C. Maximum Power Point Tracking using Fuzzy Logic Control for Photovoltaic Systems. Proceedings of the International MultiConference of Engineers and Computer Scientists 2011; 2.

[6] Borekci S, Kandemir E, Kircay A. A Simpler Single-Phase Single-Stage Grid-Connected PV System 
with Maximum Power Point Tracking Controller. Elektronika ir Elektrotechnika 2015;21/4:44-49.

[7] Chekired F, Larbes C, Rekioua D, Haddad F. Implementation of a MPPT fuzzy controller for photovoltaic systems on FPGA circuit. Energy Procedia 2011; 6: 541-549.

[8] Bounechba H, Bouzid A, Napti K, Benalla H. Comparison of perturb \& observe and fuzzy logic in maximum power point tracker for PV systems. Energy Procedia 2014;50:677-684.

[9] Jiyong L, Honghua W. Maximum Power Point Tracking of Photovoltaic Generation Based on the Fuzzy Control Method. IEEE SUPERGEN'09 2009: 1-6.

[10] Yeong-Chau K, Tsorng-Juu L, Jiann-Fuh C. Novel Maximum Power Point Tracking Controller for Photovoltaic Energy Conversion System. IEEE Transactions on Industrial Electronics 2001; 48/3.

[11] Yinqing Z, Youling Y, Yu Z, Jicheng L. MPPT Control for PV Generation System Based on an Improved Inccond Algorithm. Procedia Engineering 2012; 29: 105-109. 